\title{
Re: Falls prevention in the elderly
}

Hong Kong Med J 2015;21:287

DOI: $10.12809 / \mathrm{hkmj} 154577$

To the Editor-I read with interest the article, "Falls prevention in the elderly: translating evidence into practice," by Luk et al $^{1}$ in the April 2015 issue of Hong Kong Medical Journal. It provided timely guidance to our medical practice in this ageing population of Hong Kong. In particular, I appreciate the very useful mnemonic "AEIOU" and "ABBCCC". ${ }^{1}$ Nonetheless, A for antidepressants was used in both mnemonics. May I suggest substituting the second one with "A" for "Absence of attention of caretaker" for an additional cause of falls.

These are examples from my case files that illustrate my point.

1. An 84-year-old woman in a reputable nursing home with chronic obstructive pulmonary disease and left hemiparesis following stroke was passing a bowel motion. Her attendant could not stand the smell and left briefly. Within minutes she fell off the toilet and sustained a wrist fracture.

2. On a rainy New Year's Eve, a young woman took her 86-year-old godmother to her apartment. As she left the car and went to unlock the apartment gate, her godmother got out the car unaided but slipped and tripped over the kerb and sustained a scalp laceration.

3. A 90-year-old man with dementia, osteoporosis, and prescribed aspirin for coronary disease was admitted to hospital with extensive bruising to the lower part of the body. X-ray revealed a fractured pelvis. On further inquiry, he was cared for by two domestic helpers, but they were busy chatting with each other when he slipped off a sofa.

I fully agree with Luk et $\mathrm{al}^{1}$ that falls in the elderly are preventable. To expedite the prevention we need not only education, training, and guidelines but also continuous and uninterrupted dedication of frontline carers.

John SM Leung *, FCSHK, FHKAM (Surgery)

St Paul's Hospital, Hong Kong

* Corresponding author: leungsiumanjohn@yahoo.com.hk

\section{Reference}

1. Luk JK, Chan TY, Chan DK. Falls prevention in the elderly: translating evidence into practice. Hong Kong Med J 2015;21:165-9. 